\title{
Marriage or Carriage? Trends in Union Context and Birth Type by Education
}

Using data from 8,951 first-time mothers in the National Survey of Family Growth, the authors analyzed trends in union contexts during the transition to motherhood by social class (proxied by maternal education). Conventional classifications of union contexts as married or cohabiting were extended by classifying births relative to union status at conception. The most conventional married birth type, in which the mother was married at conception and at birth, declined sharply, but only among low- and moderately educated women. Women with lower levels of education were instead more likely to have a birth in the context of a cohabiting union formed prior to conception. In 2005-2010, the adjusted probability of a low-educated mother having a conventional married birth was $11.5 \%$, versus $78.4 \%$ for highly educated mothers. The growing disparity in union type at first birth by social class may have implications for social and economic inequality.

The American family landscape in the early 21 st century is marked by a multiplicity of options for those contemplating childbearing. Because of normative, legal, and cultural shifts, first-time

Department of Public Policy, Duke University, P.O. Box 90245, Durham, NC 27708 (cgibson@duke.edu).

* Department of Sociology, Louisiana State University, 125 Stubbs Hall, Baton Rouge, LA 70803.

Key Words: cohabiting couples with children, socioeconomic status, union formation. parents can and do choose familial arrangements other than marriage in which to conceive and bear children. This increased discretion over relationship status when women transition to motherhood has led to a multiplicity of union contexts that is more nuanced than a simple categorization of first-time mothers as either married (e.g., mothers married at the time of the birth) or cohabiting (e.g., mothers cohabiting at the time of the birth). Specifically, mothers' union contexts at birth can be categorized relative to their union contexts at the time of conception. Some mothers who are married at the time of the birth will have married prior to conception; other mothers who are married at the time of the birth will have married only after conception. Likewise, among mothers cohabiting at the time of the birth, a proportion will have conceived the pregnancy while cohabiting, whereas others will begin to cohabit after a conception has occurred.

To analyze how this multiplicity of options for new mothers has been realized, in this article we present an over-time categorization of union contexts at first birth that explicitly incorporates when the mother began her union relative to a conception (mothers with nonunion births were also considered). Data came from women who had their first child between 1985 and 2010 in the National Survey of Family Growth (NSFG), a nationally representative sample of women (see NSFG, 2010). Our study extends prior research in this area (England, Shafer, \& Wu, 2012; Lichter, 2012; Raley, 
2001) by providing a detailed typology of union contexts and by demonstrating that subtrends in marriage and cohabitation during the transition to motherhood have varied over time by social class (as measured here by maternal education). We also present the first estimates of which union context accounted for the largest decrease in the proportion of married new mothers as well as the union context that accounted for the largest increase in the proportion of cohabiting new mothers. Our typology likely has implications for resources available to families and children, given that the shifts we observe disproportionately affected lower class groups, with potential consequences for both current and future levels of inequality.

\section{BACKGROUND}

This study takes as its point of departure the well-known trends in parental union status, in particular the rise of cohabitation and singleness as alternative contexts for raising children (Bumpass \& Lu, 2000; Cherlin, 2010; Ellwood \& Jencks, 2004). In contemporary America, social pressure to marry prior to a birth has largely dissipated (Akerlof, Yellen, \& Katz, 1996; Kennedy \& Bumpass, 2008). Raley (2001) estimated that, between the early 1970s and the early 1990s, the likelihood that a single pregnant woman married by the time of the birth (e.g., had what is colloquially referred to as a "shotgun marriage") fell by 10 percentage points. Raley did not consider class differences, but other scholars have highlighted how parental union status varied greatly by social class (Isen \& Stevenson, 2011; Wilcox, 2011). England et al. (2012), working with data on women born between the early 1920 s and the late 1950 s, found that the decline in shotgun marriages was concentrated among less educated Black women.

Contemporary evaluations of union status at birth underscore how the retreat from marriage among parents has been replaced by an increase in cohabitation (Martinez, Daniels, \& Chandra, 2012). Data from the NSFG, 2006-2008 cycles, indicated that, among women unpartnered at conception, a larger proportion had cohabited by birth $(20.8 \%)$ than married (7.4\%; Lichter, 2012). In contrast, women with higher levels of education who were unpartnered at conception were more likely to change their union status by marrying rather than cohabiting, underscoring the educational differences in parental cohabitation and marital patterns found elsewhere (Wilcox, 2011).

Studies that have examined changes in the relative proportion of births born to married and cohabiting parents, however, have not decomposed trends in both married and cohabiting unions at first birth. The decline in the proportion of women who were married at the time of the birth may have occurred because relatively fewer mothers married between the conception and the birth (e.g., fewer mothers had what we term a postconception married birth, that is, a shotgun marriage). Alternatively, the decline in the proportion of married mothers may have occurred because relatively fewer mothers conceived a child within the context of a marital union (e.g., a decline in preconception married births). Likewise, a larger fraction of mothers with cohabiting births could reflect an increase in mothers who conceived a child while cohabiting (a preconception cohabiting birth); it could also be that a larger share of mothers moved in with the father after conceiving a child (a postconception cohabiting birth).

Our typology of women's relationship status during the transition to motherhood reflects both mothers' union status (e.g., if mothers married or cohabited) and birth type (if the birth was classified as married or cohabiting). For linguistic ease, we use these two concepts interchangeably. In what follows, we refer to first-time mothers as either being in a particular union context (i.e., in a preconception marriage) or as having a specific birth type (i.e., having a preconception married birth).

Because a complete typology of mothers' union types at first birth over time has thus far not been examined, the relative changes in pre- and postconception married and cohabiting births for first-time mothers is unknown. Yet trends in these subcategories of married and cohabiting births are likely to be of both demographic and developmental interest. First, the relative fraction of pre- versus postconception cohabiting births may be informative as to how cohabitation operates in the lives of new parents. Couples may cohabit and then conceive a child (as represented by a preconception cohabiting birth), or they may respond to a pregnancy by beginning to cohabit (as represented by a postconception cohabiting birth). These two types of cohabiting births may reflect differences in how new parents used cohabitation: either as a response to a 
pregnancy or as a context that operated much like marriage once did, in which individuals first form a romantic coresidential union and then have a child.

An untested but plausible assumption is that the relative levels of pre- and postconception cohabiting unions vary by maternal education. Raley (2001) found that a larger fraction of women were having preconception, as compared to postconception, births. Reed's (2006) qualitative study of low-income parents, in contrast, indicated that two thirds of cohabiting parents began their coresidential relationships after the women conceived. Akin to shotgun marriages of years past, these cohabitations would not have existed, save for the conception. Reed's results suggest that, at least among less educated women, cohabitation may have operated more as a response to a pregnancy rather than as a romantic union context per se.

A second, related reason to consider subcategories of union types at first birth is because these trends demonstrate how responses to a nonmarital conception have changed over time. The prevalence of having births within a postconception marriage has decreased in part because out-of-wedlock births are no longer socially stigmatized (Thornton \& Young-DeMarco, 2001). The decrease in postconception marriages may have been offset by increases in postconception cohabitations, suggesting that the typical response to a nonmarital conception has shifted from marriage to cohabitation (Lichter, 2012). It is also possible that, in response to a nonmarital conception, couples feel no impetus to form a union of any kind. A decline in the relative prevalence of both postconception married and cohabiting births would indicate that the inclination to form a union in response to a premarital conception has largely dissipated.

Third, a shift away from preconception marital births toward other union contexts at first birth likely has both individual- and societal-level implications. Mothers who did not marry before having their first child may be at risk of lower household resources (Addo \& Lichter, 2013; Vespa \& Painter, 2011) and more disruptive relationships (Rackin \& Gibson-Davis, 2012). Both household resources and relationship stability have been correlated with adult and child well-being (Amato, 2010; Osborne, Berger, \& Magnuson, 2012; Osborne \& McLanahan, 2007). Notably, mothers in a preconception marriage had more enduring unions than mothers in postconception marriages or preconception cohabitations (Rackin \& Gibson-Davis, 2012). Selection undoubtedly accounted for a portion of the better economic and relationship outcomes found for women in a preconception marriage. It is also the case, though, that union duration facilitates the accumulation of assets (Vespa \& Painter, 2011), and mothers in a preconception marriage may have higher levels of wealth because their unions were more stable.

A retreat from preconception married births for first-time mothers may also have implications for society, insofar as marriage plays a role in economic inequality (McLanahan \& Percheski, 2008). The financial benefits of marriage have become increasingly conveyed to those who are already economically advantaged (Isen \& Stevenson, 2011). Class differences in family formation may also undermine America's social fabric, if individuals from disparate socioeconomic backgrounds have fewer universal experiences.

These concerns about family formation and inequality may be exacerbated or mitigated depending on how changes in union and birth type are distributed across social classes. If less educated women are increasingly likely to have first births within a preconception cohabitation, rather than a preconception marriage, whereas higher class women have first births only within preconception marriage, then this class gap supports previous research on the growing marriage divide. On the other hand, if preconception marriage has declined across all social classes, then this suggests a heretofore-overlooked class uniformity in the retreat from marital unions as a context for first births.

\section{THE PRESENT STUDY}

This study is the first to examine detailed trends in union status during the transition to motherhood and to analyze the relative proportion of union contexts at first birth by maternal education over time. Because of the decline in shotgun marriages (England et al., 2012), we anticipated that at least some of the decline in the proportion of women with married births will have occurred because fewer mothers had postconception married births. Given that postconception married births were never very common, however, it is likely that the decline in postconception married births will account for only a small fraction of the overall decline in married births. 
Among women who had a first birth in a cohabiting union, we anticipated that much of the rise in cohabitation has occurred because of an increase in preconception cohabiting births rather than an increase in postconception cohabiting births (Raley, 2001). We hypothesized that pronounced differences by maternal education will exist and that the retreat from preconception married births will be concentrated among lower class women (England et al., 2012).

We were also aware that the distributions of union and births will vary nontrivially by race and ethnicity, with non-Hispanic White women having higher incidences of married births than either non-Hispanic Black or Hispanic women (Martinez et al., 2012). Research has shown that older women and women who come from more advantaged backgrounds are also more likely to have a birth in a marital union (Cherlin, 2010). Because these differences might confound educational trends, we included controls in our analyses for maternal race and ethnicity, maternal age, and whether the mother lived with both biological parents at age 14 .

\section{METHOD}

\section{Data}

The NSFG is a nationally representative survey that collects information on marriage, fertility, contraception, and other health behaviors. The NSFG samples individuals ages 15 to 44 and is nationally representative of individuals residing in American households. Response rates have generally been high (NSFG, 2010).

Data for this study come from the 1995, 2002, and 2006-2010 cycles of the NSFG (prior to 1995, the NSFG did not collect complete cohabitation histories). We restricted the analyses to women because data on men's fertility and marriage patterns were not collected until the 2002 cycles. The NSFG cycles used for the present study collected detailed retrospective histories of births, cohabitations, and marriages, making it possible to reconstruct the timing of conceptions and births relative to union formation.

The sample consisted of women whose first live birth occurred between ages 15 and 34 and occurred within 10 years of the survey date (very few children were adopted; excluding these children did not change the results). We restricted the sample to first births so that each respondent would contribute only one birth to each time period and that models would not be weighted toward women with multiple children. The age and date range restriction was imposed to address truncation and recall bias. Truncation bias occurs because retrospective data collection can produce a sample of births that will be skewed toward younger mothers at earlier time periods (e.g., the only births observed from 1970 would be for mothers who were 19 or younger when they gave birth; mothers who were 20 in 1970 would be 45 in 1995 and too old to participate in the NSFG). Recall bias arises because mothers who cohabited long before the survey may be more likely to recall those cohabitation dates inaccurately (Hayford \& Morgan, 2008). By restricting the sample to mothers who were 34 or younger when they gave birth, which included the vast majority of first births, and by including only births that occurred within the past 10 years of the survey date, our sample represented a uniform age distribution of mothers in all time periods. Although recall bias may still have been a problem, it was less likely to be an issue than if we had included a longer time frame. As a robustness check, we reran all of our models using births that occurred within 5 years of the survey date; the pattern of results was virtually identical (albeit with a smaller sample size).

Of the 18,015 mothers who had first live births between 1985 and 2010, 9,452 were observed within 10 years of their interview year. Of these 9,452 mothers, 501 were excluded because they were younger than 14 or older than 34 at the time of the birth. Our final sample size was 8,951 first-time mothers.

\section{Measures}

To establish the specific type of union at first birth (married, cohabiting, or single), we compared how mothers' monthly relationship history changed between her first birth's conception and birth date. Because we were interested in women's choices about family structure after being aware of a pregnancy, we calculated conception dates by adding 2 months to the actual date of conception (the birth date minus gestational age). Using other measures of the beginning of the pregnancy (the actual date of conception, or 7 months before the birth date) did not substantially change the results. For ease of explication, we refer to the beginning of awareness of the pregnancy as the conception 
date, even though it represented a date 2 months after the conception.

Once we had identified the conception and birth dates for the first birth, we then compared those dates to women's marital and cohabitation histories to derive five union types at first birth. Mothers with a preconception married birth were married prior to conceiving the child. Mothers with a postconception married birth married after a nonmarital conception (this group included mothers who were cohabiting at the time of conception as well mothers who were not cohabiting at conception; preliminary analyses indicated few differences between these groups). Mothers with a preconception cohabiting birth were cohabiting prior to conception, and mothers with a postconception cohabiting birth began to cohabit after conception. Mothers who were nonpartnered at both conception and at birth were classified as having a single birth. In a few cases, mothers' unions had dissolved between conception and first birth (e.g., a mother was cohabiting at conception but single at the birth); these women were categorized as single. Excluding these cases did not substantially change the results.

Our key variables of interest were the year of child's birth and the mother's educational attainment. The year of birth was divided into one of five time periods: (a) 1985-1989, (b) 1990-1994, (c) 1995-1999, (d) 2000-2004, and (e) 2005-2010. The 2005-2010 time period contained more years relative to the other groups because it had fewer births. Results were not sensitive to other year groupings. Educational attainment referred to the mother's education at the time of the survey (detailed educational measures at the time of the birth were not collected). Following prior research demonstrating the importance of considering women with a 4-year college degree as a distinct group (Isen \& Stevenson, 2011; Wilcox, 2011), we divided educational attainment into three categories: (a) women with a high school degree or less (termed low educated), (b) women with some college (moderately educated), and (c) women with at least a bachelor's degree (highly educated). The low-educated group included women without a high school diploma as well as those with a terminal high school degree because too few cases existed of women without a high school diploma to produce reliable estimates. Other covariates included mother's race and ethnicity (non-Hispanic White [omitted category], non-Hispanic Black, Hispanic, and other race and ethnicity), four dichotomous indicators of maternal age at birth (ages 15-19 [omitted category], 20-24, 25-29, or 30-34), and whether the mother lived with both of her biological parents at age 14. Mother's education was included as a control when models were not stratified by education.

Descriptive statistics of sociodemographic characteristics by union status at first birth (results not shown, but available on request) indicated that women with preconception married births had the highest levels of socioeconomic advantage, insofar as they were disproportionately White, had the highest levels of college completion, and were the oldest at the time of the first birth. Women with pre- and postconception cohabiting births and women with single births were demographically similar and had high levels of disadvantage. These mothers were disproportionately members of racial/ethnic minority groups, had relatively low levels of educational attainment, and were less likely to have lived with both biological parents at age 14 .

\section{Analytic Strategy}

We created adjusted probabilities for the five categories of union status at first birth for each time period. These probabilities were derived from multinomial logistic regression models in which we regressed union context at first birth as a function of the year of child's birth (divided into ranges, as described above), educational attainment, and the other control variables. Once we had conducted the multinomial logistic regression models, we then predicted the probability of mothers having one of the five union contexts at first birth, holding other covariates at their means. The predicted probabilities were therefore adjusted to account for differences over time in education, race and ethnicity, age, and intact family status in the mother's family of origin. Coefficients from the multinomial logistic regression models that were used to generate the predicted probabilities are not presented but are available on request. For ease of interpretation, predicted probabilities are expressed in percentages.

For each set of results, we present the relative change in the proportion of first births that occurred in each union context. For the marital and cohabiting birth subcategories, we further indicated how change in that subcategory 
accounted for changes in the larger category (e.g., the amount of decline in married births that was accounted for by a decline in postconception births). We also tested whether the probabilities observed in the last time period (e.g., 2005-2010) differed significantly from the probabilities observed in earlier time periods. We chose 2005-2010 as the point of comparison to see whether family formation changes continued to shift until the last half of the 2000s. We weighted all models to be nationally representative, using weights provided by the NSFG. Predicted probabilities were constructed for the sample as a whole and then for each of the educational attainment groups.

\section{RESULTS}

\section{Trends in Marital, Cohabiting, and Single Births}

The first set of results presents the over-time distribution of the six union contexts at first birth (see Table 1). These probabilities have not been adjusted for covariates and represent the statistical equivalent of estimating means of union contexts by birth year. The results indicated that, over the observation period, the percentage of first-time mothers in marital unions decreased sharply, with an attendant rise in first-time mothers in cohabiting unions. The percentage of first-time mothers who were married at the time of the birth decreased from $67.8 \%$ in $1985-1989$ to $45.5 \%$ in $2005-2010$, a $33 \%$ decrease. Over the same time period, the percentage of first-time mothers who were cohabiting at the time of the birth rose by $194 \%$, from $10.4 \%$ to $30.4 \%$. The proportion of first-time mothers who were single at the time of birth remained relatively constant, averaging approximately $23 \%$ of all births, and the proportion did not change significantly between 1985-1989 and 2005-2010.

We note that our estimate of $54.5 \%$ of women with a nonmarital birth in 2005-2010 was higher than the $43 \%$ reported by Payne, Manning, and Brown (2012) in their analysis of the same cycle of the NSFG. The higher proportion of nonmarital births in our analyses occurred because of the sample under investigation. Previous research has indicated that first births are more likely to be nonmarital than higher order births and that older women are more likely to have married births than younger women (Musick, 2002). When we relaxed our sample restrictions and included all births to all women regardless of age or parity, we produced the same estimates as Payne et al.

In terms of subcategories, the results indicated a sharp decrease in the proportion of new mothers with a preconception married birth, with a concordant rise in the proportion of new mothers with a preconception cohabiting birth. The relative prevalence of unions formed after a conception was small throughout the observed time period. Of note, though, is that the percentage of first births to mothers in postconception married unions fell by $27 \%$ between the first and last periods, whereas the percentage of first births to mothers in postconception cohabiting unions rose by $142 \%$.

\section{Adjusted Trends in Union Contexts at First Birth}

The next set of results presents the adjusted predicted probabilities for each of the five union contexts at first birth (see Table 2). The probability of a first-time mother having a married birth declined by $47 \%$ (from $67.4 \%$ to $35.8 \%$ ), whereas the probability of having a cohabiting birth increased by $241 \%$ (from

Table 1. Descriptive Statistics of Union Status at First Birth, by Year of Child's Birth $(\mathrm{n}=8,951)$

\begin{tabular}{lcccccc}
\hline Union status & $1985-1989$ & $1990-1994$ & $1995-1999$ & $2000-2004$ & $2005-2010$ & As relative \% change \\
\hline Married & $\mathbf{6 7 . 8}$ & $\mathbf{6 2 . 0}$ & $\mathbf{5 9 . 3}$ & $\mathbf{5 4 . 8}$ & 45.5 & -33.0 \\
Preconception & $\mathbf{5 9 . 1}$ & $\mathbf{5 3 . 9}$ & $\mathbf{5 1 . 5}$ & $\mathbf{4 9 . 2}$ & 39.1 & -33.8 \\
Postconception & 8.7 & 8.1 & 7.8 & 5.6 & 6.3 & -27.2 \\
Cohabiting & $\mathbf{1 0 . 4}$ & $\mathbf{1 2 . 9}$ & $\mathbf{1 7 . 8}$ & $\mathbf{2 3 . 9}$ & 30.4 & 193.5 \\
Preconception & $\mathbf{8 . 2}$ & $\mathbf{1 0 . 4}$ & $\mathbf{1 4 . 2}$ & $\mathbf{1 9 . 2}$ & 25.2 & 207.2 \\
Postconception & $\mathbf{2 . 2}$ & $\mathbf{2 . 5}$ & 3.6 & 4.8 & 5.3 & 141.9 \\
Single & 21.8 & 25.1 & 22.9 & 21.3 & 24.1 & 10.5 \\
\hline
\end{tabular}

Note: Numbers represent the proportion of first births falling into that union status in that year. Percentages in boldface type were significantly different at the 5\% level than 2005-2010 coefficients for the same birth type. 
Table 2. Adjusted Probabilities of Union Status at First Birth, by Year of Child's Birth $(\mathrm{n}=8,951)$

\begin{tabular}{|c|c|c|c|c|c|c|c|c|}
\hline \multirow[b]{2}{*}{ Union status } & \multirow[b]{2}{*}{ 1985-1989 } & \multirow[b]{2}{*}{ 1990-1994 } & \multirow[b]{2}{*}{ 1995-1999 } & \multirow[b]{2}{*}{ 2000-2004 } & \multirow[b]{2}{*}{ 2005-2010 } & \multirow[b]{2}{*}{$\begin{array}{c}\text { As relative } \% \\
\text { change }\end{array}$} & \multicolumn{2}{|c|}{ As $\%$ of change in } \\
\hline & & & & & & & $\begin{array}{l}\text { Marital } \\
\text { births }\end{array}$ & $\begin{array}{c}\text { Cohabiting } \\
\text { births }\end{array}$ \\
\hline Married & 67.4 & 59.3 & 53.4 & 47.8 & 35.8 & -46.9 & & \\
\hline Preconception & $\mathbf{5 7 . 4}$ & 49.4 & 43.7 & 40.6 & 27.6 & -52.0 & 94.5 & \\
\hline Postconception & 10.0 & 9.8 & 9.7 & 7.1 & 8.2 & -17.5 & 5.5 & \\
\hline Cohabiting & 11.1 & 14.3 & 21.2 & 28.4 & 37.7 & 241.3 & & \\
\hline Preconception & 8.9 & 11.7 & 17.3 & 23.1 & 31.4 & 251.6 & & 84.4 \\
\hline Postconception & 2.1 & 2.6 & 3.9 & 5.3 & 6.3 & 197.6 & & 15.6 \\
\hline Single & 21.5 & 26.4 & 25.4 & 23.9 & 26.5 & 23.0 & & \\
\hline
\end{tabular}

Note: Probabilities are expressed as percentages.

$11.1 \%$ to $37.7 \%$ ). The proportion of mothers with single births increased more modestly, rising $23 \%$ (from $21.5 \%$ to $26.5 \%$ ).

Adjusted results were substantively consistent with the unadjusted probabilities (see Table 1), although adjusting for covariates resulted in a lower relative prevalence of married births in 2005-2010. Analyses (not shown) indicated that differences between the unadjusted and adjusted probabilities arose because of age: Younger mothers were less likely to have a married birth, and adjusting for age decreased the relative fraction of married births. In general, the unadjusted and adjusted results for both the full sample and by maternal education were substantively quite comparable (see Table A1 on the Journal of Marriage and Family website, http://onlinelibrary.wiley.com/journal/10.1111/ (ISSN)1741-3737, for education group results). Because we judged it important to control for the shifting demographic composition of mothers, we concentrate on the adjusted results throughout the rest of the study.

Declines in the proportion of preconception married births accounted for $95 \%$ of the overall decline in married births (see Table 2). The adjusted probability of a new mother having a preconception married birth fell from $57.4 \%$ in $1985-1989$ to $27.6 \%$ in $2005-2010$. The proportion of births that were within a postconception marriage fell only slightly and accounted for only $5.5 \%$ of the overall decline in married births.

Just as the majority of variance in married births was explained by changes in preconception married births, the majority of variance in cohabiting births was explained by changes in preconception cohabiting births. The relative proportion of preconception cohabiting births rose by $252 \%$, representing about one third of all first births in 2005-2010 and accounting for $84 \%$ of the increase in cohabiting births. The proportion of mothers with a postconception cohabiting birth rose significantly over the observed time period but remained in the single digits. Changes in the relative proportion of postconception cohabiting births accounted for only $16 \%$ of the overall increase of cohabiting births.

The results also indicated that preconception married births and increases in the proportion of preconception cohabiting births continued into the 2000s. The probabilities of preconception married and preconception cohabiting births in 2000-2004 differed significantly from the 2005-2010 probabilities. The relative prevalence of single births, in contrast, has remained fairly constant since the early 1990s.

\section{Analyses by Maternal Education}

We next present adjusted probabilities of mothers' union type at first birth, divided by maternal educational status (see Table 3; unadjusted probabilities are available in online Table A1). Overall, mothers with higher levels of education were more likely than those with lower levels of education to have a married birth and less likely to have a cohabiting or single birth.

Subcategory results indicated a few key points. First, preconception cohabitation increasingly replaced preconception marriage, but this trend was most pronounced for low and moderately educated mothers. This is illustrated in Figures 1 through 3, in which we have plotted the predicted probabilities of preconception married births versus preconception cohabiting births by maternal educational status. In each figure, the 
Table 3. Adjusted Predicted Probability of Union Status at First Birth, by Maternal Educational Attainment and Year of Child's Birth

\begin{tabular}{|c|c|c|c|c|c|c|c|c|}
\hline \multirow[b]{2}{*}{ Education level } & \multirow[b]{2}{*}{ 1985-1989 } & \multirow[b]{2}{*}{ 1990-1994 } & \multirow[b]{2}{*}{ 1995-1999 } & \multirow[b]{2}{*}{$2000-2004$} & \multirow[b]{2}{*}{ 2005-2010 } & \multirow{2}{*}{$\begin{array}{c}\text { As } \\
\text { relative \% } \\
\text { change }\end{array}$} & \multicolumn{2}{|c|}{ As $\%$ of change in } \\
\hline & & & & & & & $\begin{array}{c}\text { Marital } \\
\text { births }\end{array}$ & $\begin{array}{c}\text { Cohabiting } \\
\text { births }\end{array}$ \\
\hline \multicolumn{9}{|l|}{ Low $(n=4,833)$} \\
\hline Married & 51.6 & 38.5 & 31.7 & 27.5 & 16.6 & -67.9 & & \\
\hline Preconception & 39.1 & 29.9 & 23.5 & 21.5 & 11.5 & -70.6 & 78.8 & \\
\hline Postconception & 12.5 & 8.7 & 8.2 & 5.9 & 5.1 & -59.6 & 21.2 & \\
\hline Cohabiting & 16.9 & 20.6 & 30.2 & 38.8 & 45.1 & 167.2 & & \\
\hline Preconception & 13.5 & 16.9 & 24.5 & 32.1 & 39.1 & 189.9 & & 90.9 \\
\hline Postconception & 3.4 & 3.7 & 5.7 & 6.7 & 5.9 & 76.0 & & 9.1 \\
\hline Single & 31.5 & 40.9 & 38.0 & 33.8 & 38.4 & 21.8 & & \\
\hline \multicolumn{9}{|l|}{ Moderate $(n=2,370)$} \\
\hline Married & 67.1 & 65.9 & 57.3 & 47.2 & 40.4 & -39.7 & & \\
\hline Preconception & 58.8 & 52.6 & 45.4 & 39.4 & 32.5 & -44.7 & 98.6 & \\
\hline Postconception & 8.3 & 13.4 & 11.9 & 7.7 & 7.9 & -4.5 & 1.4 & \\
\hline Cohabiting & 9.0 & 12.2 & 20.5 & 29.1 & 39.6 & 342.0 & & \\
\hline Preconception & 6.8 & 10.3 & 17.9 & 23.6 & 29.8 & 336.0 & & 75.0 \\
\hline Postconception & 2.1 & 1.8 & 2.7 & 5.6 & 9.8 & 361.3 & & 25.0 \\
\hline Single & 24.0 & 21.9 & 22.3 & 23.7 & 20.0 & -16.7 & & \\
\hline \multicolumn{9}{|l|}{$\operatorname{High}(n=1,748)$} \\
\hline Married & 90.5 & 91.7 & 94.6 & 92.9 & 87.1 & -3.7 & & \\
\hline Preconception & 89.3 & 88.6 & 90.9 & 89.1 & 78.4 & -12.2 & 322.3 & \\
\hline Postconception & 1.2 & 3.1 & 3.7 & 3.8 & 8.7 & 624.2 & -222.3 & \\
\hline Cohabiting & 4.8 & 4.3 & 2.5 & 3.9 & 9.4 & 94.6 & & \\
\hline Preconception & 4.8 & 3.1 & 1.5 & 2.9 & 8.7 & 79.5 & & 100.0 \\
\hline Postconception & 0.0 & 1.2 & 1.1 & 1.0 & 0.7 & - & & - \\
\hline Single & 4.7 & 4.0 & 2.9 & 3.2 & 3.5 & -25.6 & & \\
\hline
\end{tabular}

Note: Probabilities are expressed as percentages. Coefficients in boldface type were significantly different at the $5 \%$ level than 2005-2010 coefficients of the same birth type. Models controlled for maternal race and ethnicity, maternal age, and whether the mother lived with both biological parents when she was 14. Dashes indicate that change cannot be calculated because probabilities in 1985-1989 were 0 .

darker lines represent the predicted probabilities, with the light dashed lines representing the $95 \%$ confidence intervals. As the figures make clear, the rise of preconception cohabiting births relative to preconception married births was concentrated in the groups with lower education. The relative likelihood that a first birth was conceived after marriage remained roughly constant among highly educated mothers. Among mothers in the low-educated group, in 2005-2010, the predicted probability of having a preconception cohabiting birth was 3.5 times more likely than the predicted probability of having a preconception married birth $(39.1 \%$ and $11.5 \%$, respectively). Among the moderately educated mothers, the likelihood of having a preconception married birth $(32.5 \%)$ was statistically equivalent to that of a preconception cohabiting birth (29.8\%; statistical test not shown).

Second, the gap in preconception cohabiting births for highly educated mothers relative to low- and moderately educated mothers became more pronounced over time. In 1985-1989, the difference between the low- and highly educated group in the probability of preconception cohabiting births was approximately nine percentage points; the difference between the moderately educated and the highly educated was two percentage points. By 2005-2010, the gap in the prevalence of preconception cohabiting births grew, for the low- versus highly educated groups, to 31 percentage points and, for moderately versus highly educated mothers, 21 percentage points. We found a similar widening gap across education groups for women with 
Figure 1. Preconception Married Versus Preconception Cohabiting Births, Low-Educated Mothers.

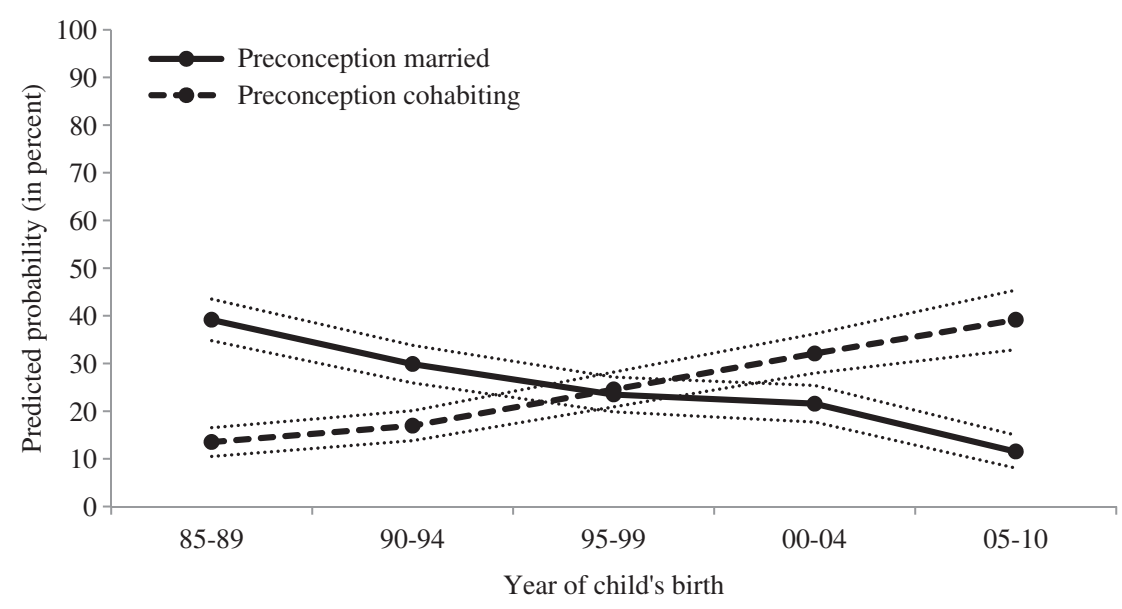

Note: Black lines represent adjusted probabilities. Light dotted lines depict 95\% confidence intervals.

Figure 2. Preconception Married Versus Preconception Cohabiting Births, Moderately Educated Mothers.

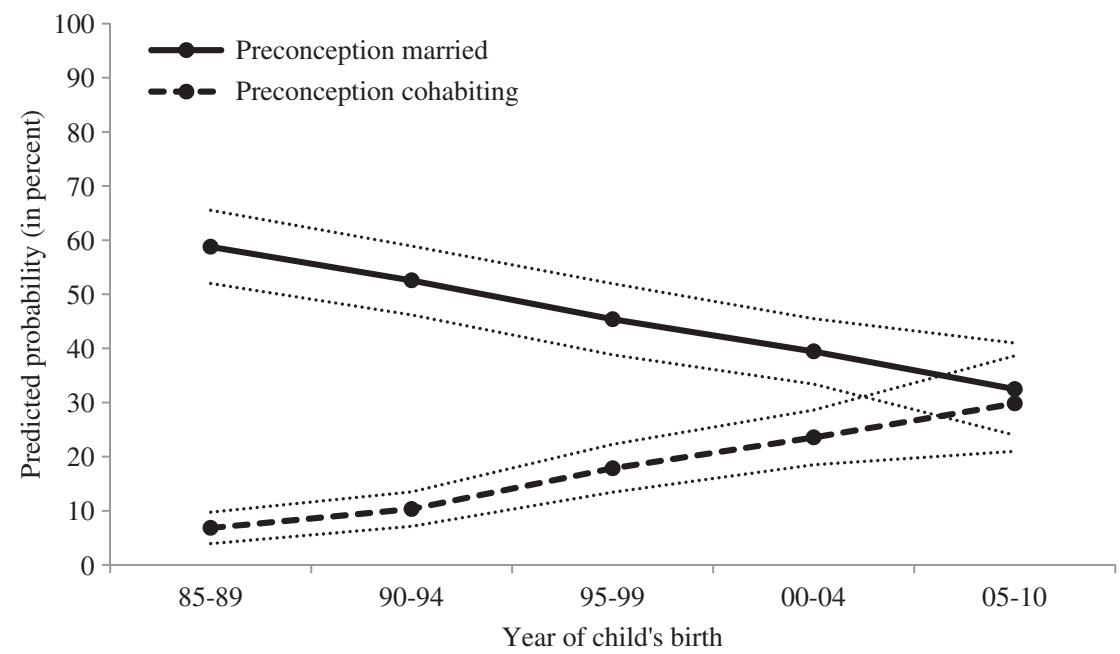

Note: Black lines represent adjusted probabilities. Light dotted lines depict $95 \%$ confidence intervals.

preconception married births. Differences in family formation patterns by education emerged because low- and moderately educated mothers had increasingly similar patterns of union status at first birth. The results for both groups diverged from those of the highly educated group, leaving the highly educated increasingly distinct in terms of union status.

First-time highly educated mothers did change their union contexts at first birth somewhat over time (see Table 3). Although the probability of a highly educated mother having a married birth remained stable throughout the study period (about 90\%), highly educated mothers did have a significant decrease in the proportion of preconception married births as well as a significant increase in the proportion of postconception married births. Notably, the decline in the proportion of births to mothers in a preconception married union occurred only between 2005 and 2010. Additional analyses (not shown) indicated that this decline occurred 
Figure 3. Preconception Married Versus Preconception Cohabiting Births, Highly Educated Mothers.

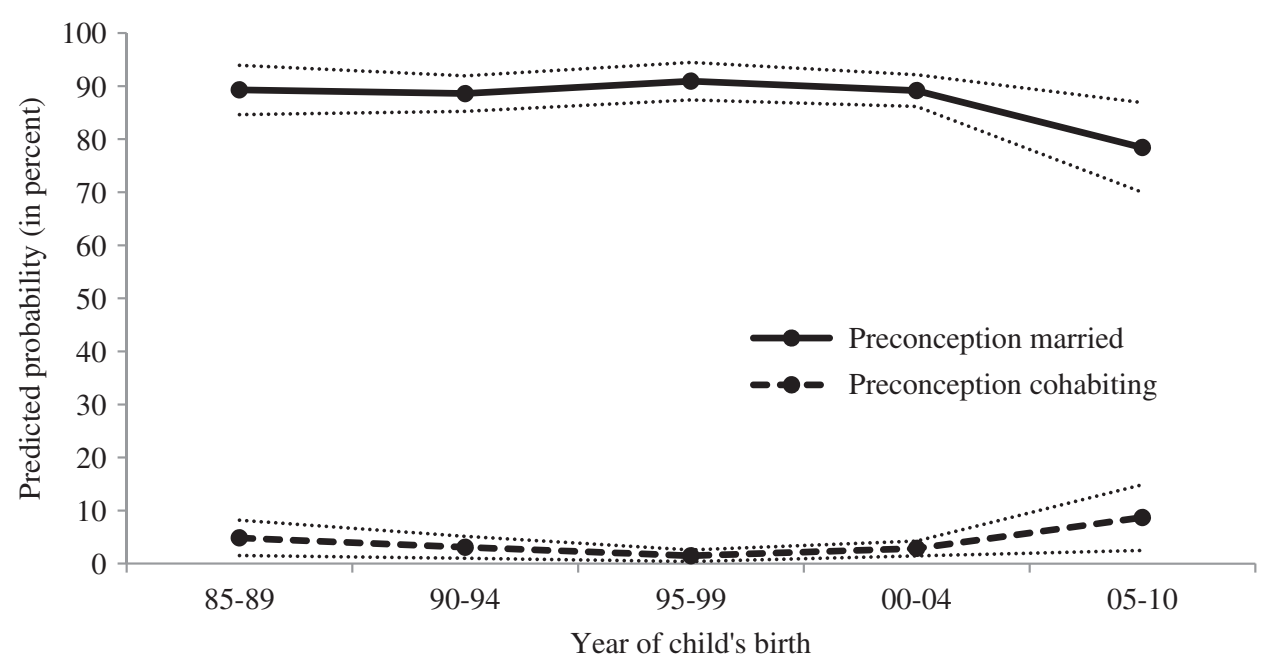

Note: Black lines represent adjusted probabilities. Light dotted lines depict 95\% confidence intervals.

in part because we selected mothers under age 34. This selection criterion disproportionately affects well-educated mothers, who, over the study period, were increasingly older at first birth. If the sample included mothers ages 15-44, then the adjusted probability of a highly educated mother having a preconception married birth rose to $84 \%$ (results not shown).

When considered in conjunction with the results for low- and moderately educated mothers, the results suggest that, over time, preconception marriage became increasingly concentrated among the best educated. In 1985-1989, low-educated mothers accounted for $21 \%$ of all preconception married births (e.g., $39.1 /[39.1+58.8+89.3]$ ), and highly educated mothers accounted for 48\%. By 2005-2010, low-educated mothers accounted for only $9 \%$ of all preconception married births, and highly educated mothers accounted for $64 \%$.

The third notable subtrend result was that, among low- and moderately educated mothers, the proportion of first-time mothers with a postconception cohabiting birth was either as common as or exceeded the proportion of postconception married births. Between 1980-1995 and 2005-2010, the probability of a low-educated mother having a postconception married birth decreased by $60 \%$. The probabilities for postconception cohabiting births increased by $76 \%$ (albeit with a very low base rate). The moderately educated mothers had a marked increase (361\%) in the probabilities of postconception cohabiting births: By 2005-2010, nearly one out of 10 new mothers formed her cohabiting union after conception. Very few highly educated mothers had postconception cohabiting births.

\section{DISCUSSION}

This study, in which we investigated union context at first birth, has documented a familial landscape characterized chiefly by a drastic reduction in preconception married births among low-educated mothers. Low-educated mothers (and, to a lesser extent, moderately educated mothers) instead increasingly realized their first births in the context of a cohabiting union formed prior to conception. Highly educated mothers, unlike their less educated peers, were consistently likely to have first births in the most conventional of union contexts: a marriage established prior to conception.

For low- and moderately educated mothers, the familial landscape discussed here was highly dynamic. In just 25 years, among low-educated mothers, preconception married unions went from the most common to a distant third behind preconception cohabiting and single unions. Among moderately educated mothers, the probability of having a preconception married 
birth was halved, while the probability of having a preconception cohabiting birth quadrupled. We also saw little evidence that trends in union status at first birth have stabilized, suggesting that further change in the relative prevalence of preconception marriage and preconception cohabitation is likely.

We draw two conclusions from these swift and dramatic changes in union contexts for lowand moderately educated first-time mothers. First, we found some evidence that education moderated the relative levels of postconception cohabitation, but not as we had anticipated. We had hypothesized that postconception cohabitation would be most common among low-educated mothers (Reed, 2006). In fact, postconception cohabiting births were most common among moderately educated mothers and, in 2005-2010, accounted for one in 10 births. The $361 \%$ increase in postconception cohabiting births among moderately educated mothers was consistent with the hypothesis that cohabitation, at least for a select group of mothers, functioned as a response to a pregnancy. For low-educated mothers, however, we found that the vast majority of couples with a cohabiting birth had established their union prior to conception (Raley, 2001). The results underscored, for low-educated mothers, the normalization of cohabitation as a birth context and suggest that it operated much as marriage once did: as a common family formation path whereby couples first establish their romantic union and then have children.

Second, even though the relative fraction of low- and moderately educated women with a postconception cohabiting birth was small, more women had a postconception cohabiting birth than a preconception married birth. For low- and moderately educated women, it does not appear that the behavioral pattern of forming a union before a first birth had dissipated; instead, the response changed from marriage to cohabitation (Lichter, 2012). When low- and moderately educated women were combined, the percentage of first births born into postconception unions was consistent over time and varied between 13\% and $14 \%$. Yet the type of postconception union varied over time. In 1985-1989, after a nonmarital conception, low and moderately educated mothers were nearly four times more likely to marry than to cohabit; by 2005-2010, they were 1.2 times more likely to cohabit than to marry. This displacement of marriage with cohabitation again speaks to the mainstream role of cohabitation and its increasing replacement of marriage.

As noted above, highly educated women exhibited little change in their union contexts at the time of first birth in the past quarter century. Although highly educated women have increased the incidence of cohabitation before marriage (Cherlin, 2010), their union status at first birth has remained nearly the same and exhibited a striking consistency. We also note that the small proportion of highly educated women with a nonmarital birth runs counter to a popular narrative that a large proportion of highly educated women now have children by themselves. Our results revealed that the probability of a highly educated mother having a single birth was quite small (around 3\%). These probabilities actually declined over the course of our study (albeit not significantly). Our evidence indicated that, despite perceptions to the contrary, highly educated women having a child without a partner-specifically, without a married partner - was quite rare.

We found that preconception marriage - the most conventional union type and the union type associated with the longest duration - has become increasingly concentrated among the highly educated. Marriages established before conception may be the most advantageous type for both adults and children, insofar as such marriages have been correlated with the highest levels of resources and stability (Rackin \& GibsonDavis, 2012; Vespa \& Painter, 2011). We cannot address whether the association between preconception marriage and well-being is causal or correlational but, if this type of marriage does convey more benefits than other union types, then one implication of our results is that the longest lasting and perhaps most materially beneficial union types were concentrated among mothers who were already economically advantaged.

Overall, this study has demonstrated that low- and moderately educated mothers had increasingly similar trends in their union contexts at first birth, with both groups moving away from highly educated mothers. Relative levels of union status at first birth did not completely converge between low- and moderately educated mothers: In 2005-2010, moderately educated mothers had higher fractions of preconception marriage and lower fractions of postconception cohabitation. Nevertheless, the trends exhibited by low and moderately educated mothers - fewer preconception marriages, 
more preconception cohabitation, more postconception cohabitation - were strikingly similar.

This differential shift by social class likely has consequences for inequality. Marriage and economic well-being have a bidirectional association: Just as economic resources affect who marries (McLanahan \& Percheski, 2008; Smock, Manning, \& Porter, 2005), marriage affects economic resources (Antonovic \& Town, 2004; Bardasi \& Taylor, 2008; Thomas \& Sawhill, 2005). Given the relative lack of social mobility across generations (Beller \& Hout, 2006), an increasing fraction of children growing up outside of married-parent homes may have fewer economic resources as adults and be less likely to marry themselves. This growing divide may also affect social inequality, given that family patterns that are sharply divided by social class may contribute to the increasing polarization seen in America. We can only speculate on the consequences of family structure for inequality but suggest that this is a fruitful area for future research.

Limitations to this study should be noted. We have tacitly assumed that a postconception marriage represents a match between the biological parents but, because of data limitations, could not directly verify this assumption (matching children to biological fathers became possible only in 2007). Scholars have also noted that it may be difficult to pinpoint when cohabitations began, because these relationships may not be defined by a clear starting point (Manning \& Smock, 2005). Moreover, women in more tenuous romantic relationships may be less likely to accurately date their unions (Teitler, Reichman, \& Koball, 2006), suggesting that certain union contexts (e.g., postconception cohabitation) may be misreported. We cannot address this problem directly but, assuming the error in measuring cohabitation was constant over time, our estimates should not be biased.

We had to exclude the 1988 cycle of the NSFG because that cycle did not collect complete information on women's cohabitation history. It excluded higher order cohabitations that were not ongoing as well as cohabiting spells with a man the mother did not marry. Supplementary analyses that included the 1988 NSFG indicated that trends that were reported here (decreases in preconception marriage and increases in preand postconception cohabitation) became more pronounced when unions in the 1970s were compared with unions in the 2000s. Because of the likely undercount of cohabitation, results with the 1988 NSFG were not included.

Finally, our study was also limited in that we could not produce reliable estimates for preand postconception births for Black or Hispanic women. These estimates were unreliable because of small sample sizes and low base rates of marriage for racial/ethnic minority women. Aggregate trends (results not shown) for married, cohabiting, and single births were consistent with previous research (Smock \& Greenland, 2010), insofar as White mothers had the highest proportions of married births, Black women had the lowest proportions, and Hispanics fell in between.

Our findings are important not only because they highlight the evolving role of marriage and cohabitation but also because they show the changing distribution of union type at first birth by maternal education. These union contexts are likely to affect the well-being of the adults and children involved through their levels of economic resources and the intergenerational transmission of social class. We suggest that future research should be concerned not only with the trajectories couples take toward family formation but also with how those trajectories inform larger issues of social well-being, class, and inequality. This study has highlighted how the relative ordering of marriage and cohabitation during the transition to motherhood has changed and suggests that this evolution is likely to have profound demographic and economic implications.

\section{Note}

We thank Paula England, Anna Gassman-Pines, and S. Phillip Morgan for feedback. Christina Gibson-Davis gratefully acknowledges support from the WT Grant foundation.

\section{SUPPORTING INFORMATION}

Additional supporting information may be found in the online version of this article:

Table A1. Comparison of Unadjusted and Adjusted Union Status at First Birth, by Maternal Educational Attainment and Year of Child's Birth

\section{REFERENCES}

Addo, F. R., \& Lichter, D. T. (2013). Marriage, marital history, and Black-White wealth differentials among older women. Journal of Marriage and Family, 75, 342-362. doi:10.1111/jomf.12007 
Akerlof, G. A., Yellen, J. T., \& Katz, M. L. (1996). An analysis of out-of-wedlock childbearing in the United States. Quarterly Journal of Economics, 111, 278-317. doi:10.2307/2946680

Amato, P. R. (2010). Research on divorce: Continuing trends and new developments. Journal of Marriage and Family, 72, 650-666. doi:10.1111/j.17413737.2010.00723.x

Antonovic, K., \& Town, R. (2004). Are all good men married? Uncovering the sources of the marital wage premium. American Economic Review, 94, 317-321. http://www.jstor.org/stable/3592902

Bardasi, E., \& Taylor, M. G. (2008). Marriage and wages: A test of the specialization hypothesis. Economica, 75, 569-591. doi:10.1111/j.14680335.2007.00630.x

Beller, E., \& Hout, M. (2006). Intergenerational social mobility: The United States in comparative perspective. The Future of Children, 16, 19-36. doi:10.1353/foc.2006.0012

Bumpass, L., \& Lu, H.-H. (2000). Trends in cohabitation and implications for children's family contexts in the United States. Population Studies, 54, 29-41. doi:10.1080/713779060

Cherlin, A. J. (2010). Demographic trends in the United States: A review of research in the 2000s. Journal of Marriage and Family, 72, 403-419. doi:10.1111/j.1741-3737.2010.00710.x

Ellwood, D. T., \& Jencks, C. (2004). The uneven spread of single-parent families: What do we know? Where do we look for answers? In K. Neckerman (Ed.), Social inequality (pp. 3-77). New York: Russell Sage Foundation.

England, P., Shafer, E. F. \& Wu, L. L. (2012). Premarital conceptions, postconception ("shotgun") marriages, and premarital first births: Education gradients in U.S. cohorts of White and Black women born 1925-1959. Demographic Research, 27, 153-166. doi:10.4054/DemRes.2012.27.6

Hayford, S. R., \& Morgan, S. P. (2008). The quality of retrospective data on cohabitation. Demography, 45, 129-141. doi:10.1353/dem.2008.0005

Isen, A., \& Stevenson, B. (2011). Women's education and family behavior: Trends in marriage, divorce and fertility. In J. B. Shoven (Ed.), Demography and the economy (pp. 107-142). Chicago: University of Chicago Press.

Kennedy, S., \& Bumpass, L. (2008). Cohabitation and children's living arrangements: New estimates from the United States. Demographic Research, 19, 1663-1692. doi:10.4054/DemRes.2008. 19.47

Lichter, D. T. (2012). Childbearing among cohabiting women: Race, pregnancy, and union transitions. In A. Booth, S. L. Brown, N. S. Landale, W. D. Manning, \& S. M. McHale (Eds.), Early adulthood in a family context (pp. 209-220). New York: Springer Publishing. doi:10.1007/9781-4614-1436-0_13
Manning, W. D., \& Smock, P. J. (2005). Measuring and modeling cohabitation: New perspectives from qualitative data. Journal of Marriage and Family, 67, 989-1002. doi:10.1111/j.17413737.2005.00189.x

Martinez, G., Daniels, K., \& Chandra, A. (2012). Fertility of men and women aged 15-44 years in the United States: National Survey of Family Growth, 2006-2010. Report No. 51, National Center for Health Statistics, Hyattsville, MD.

McLanahan, S., \& Percheski, C. (2008). Family structure and the reproduction of inequalities. Annual Review of Sociology, 34, 257-276. doi:10.1146/annurev.soc.34.040507.134549

Musick, K. (2002). Planned and unplanned childbearing among unmarried women. Journal of Marriage and Family, 64, 915-929. doi:10.1111/j.17413737.2002.00915.x

National Survey of Family Growth. (2010). About the National Survey of Family Growth. Retrieved from http://www.cdc.gov/nchs/nsfg/about_nsfg.htm

Osborne, C., Berger, L. M., \& Magnuson, K. (2012). Family structure transitions and changes in maternal resources and well-being. Demography, 49, 23-47. doi:10.1007/s13524-011-0080-x

Osborne, C., \& McLanahan, S. (2007). Partnership instability and child well-being. Journal of Marriage and Family, 69, 1065-1083. doi:10.1111/j.1741-3737.2007.00431.x

Payne, K. K., Manning, W. D., \& Brown, S. (2012). Unmarried births to cohabiting and single mothers, 2005-2010. Report No. FP-12-06, National Center for Family \& Marriage Research, Bowling Green State University, Bowling Green, $\mathrm{OH}$.

Rackin, H., \& Gibson-Davis, C. M. (2012). The role of pre- and postconception relationships for first time parents. Journal of Marriage and Family, 74, 526-539. doi:10.1111/j.1741-3737.2012. 00974.x

Raley, R. K. (2001). Increasing fertility in cohabiting unions: Evidence for the Second Demographic Transition in the United States? Demography, 38, 59-67. doi:10.1353/dem.2001. 0008

Reed, J. M. (2006). Not crossing the "extra line": How cohabitors with children view their unions. Journal of Marriage and Family, 68, 1117-1131. doi:10.1111/j.1741-3737.2006.00318.x

Smock, P. J., \& Greenland, F. R. (2010). Diversity in pathways to parenthood: Patterns, implications, and emerging research directions. Journal of Marriage and Family, 72, 576-593. doi:10.1111/j.1741-3737.2010.00719.x

Smock, P. J., Manning, W. D., \& Porter, M. (2005). "Everything's there except money": How money shapes decisions to marry among cohabitors. Journal of Marriage and Family, 67, 680-696. doi:10.1111/j.1741-3737.2005.00162.x 
Teitler, J. O., Reichman, N., \& Koball, H. (2006). Contemporaneous versus retrospective reports of cohabitation in the Fragile Families survey. Journal of Marriage and Family, 68, 469-477. doi:10.1111/j.1741-3737.2006.00265.x

Thomas, A., \& Sawhill, I. (2005). For love and money? The impact of family structure on income. The Future of Children, 15, 57-74. doi:10.1353/foc. 2005.0020

Thornton, A., \& Young-DeMarco, L. (2001). Four decades of trends in attitudes toward family issues in the United States: The 1960s through the 1990s.
Journal of Marriage and Family, 63, 1009-1037. doi:10.1111/j.1741-3737.2001.01009.x

Vespa, J., \& Painter, M. A., III (2011). Cohabitation history, marriage, and wealth accumulation. Demography, 48, 983-1004. doi:10.1007/s13524011-0043-2

Wilcox, W. B. (2011). The state of our unions 2010: When marriage disappears: The new middle America. Retrieved from http://stateofourunions.org/2010/when-marriagedisappears.php 
Reproduced with permission of the copyright owner. Further reproduction prohibited without permission. 